\title{
Avaliação de métodos para superação de dormência na germinação de Ormosia arborea (Vell.) Harms
}

\author{
Walquíria Fernanda Teixeira* \\ Evandro Binotto Fagan \\ Derblai Casaroli \\ Sabrina de Carvalho Canedo \\ Kamilla Alves Barbosa \\ Núcleo de Pesquisa em Fisiologia Vegetal, Agroclimatologia, Modelagem na Agricultura e Irrigação, \\ Faculdade de Engenharia e Ciências Agrárias, Centro Universitário de Patos de Minas \\ CEP 38.702-054, Patos de Minas - MG, Brasil \\ *Autor para correspondência \\ walquiria_bio@yahoo.com.br
}

\section{Resumo}

O objetivo do trabalho foi avaliar o efeito de diferentes métodos de quebra de dormência na germinação de Ormosia arborea. Foram utilizados os seguintes tratamentos: imersão em água por $72 \mathrm{~h}$; escarificação química com ácido sulfúrico 100\%; escarificação mecânica + embebição por $24 \mathrm{~h}$ e um grupo controle, sendo que, cada um desses tratamentos foi realizado com fotoperíodos de $12 \mathrm{~h}$ e $0 \mathrm{~h}$. As sementes foram submetidas aos tratamentos de luminosidade durante o período do teste de germinação em duas câmaras de germinação do tipo B.O.D. Utilizou-se o delineamento inteiramente casualizado, com quatro repetições. Maiores percentagens de germinação foram observadas nos tratamentos com escarificação química. Não foram encontradas diferenças de percentagem de germinação entre os fotoperíodos de $0 \mathrm{~h}$ e $12 \mathrm{~h}$ na espécie estudada. Concluiu-se que as sementes de Ormosia arborea apresentam maiores percentuais de germinação quando submetidas à escarificação química e que a luminosidade não exerce influencia sobre a germinação dessa espécie.

Palavras-chave: Dormência de sementes, Luz, Ormosia arborea

\section{Abstract}

Evaluation of methods to overcome dormancy in the germination of Ormosia arborea (Vell.) Harms. The work aimed to evaluate the effect of different methods to overcome dormancy in the germination of Ormosia arborea. The following treatments were used: $72 \mathrm{~h}$ of water immersion; chemical scarification with $100 \%$ sulfuric acid; mechanical scarification $+24 \mathrm{~h}$ of imbibing and group control, each treatment being carried out with $12 \mathrm{~h}$ and $0 \mathrm{~h}$ photoperiods. The seeds undertook luminosity treatments within the period of germination testing in two germination chambers, BOD model. A completely randomized design was used, with four replications. Greater germination percentages were observed in treatments with chemical scarification. There were no germination percentage differences between the $0 \mathrm{~h}$ and $12 \mathrm{~h}$ photoperiods in the species under study. One concludes Ormosia arborea seeds present greater germination percentages when undertaking chemical scarification, and luminosity has no influence over the germination of this species.

Key words: Light, Ormosia arborea, Seeds dormancy 


\section{Introdução}

O fenômeno de dormência em sementes advém de uma adaptação das espécies ás condições ambientais em que se reproduzem. Este mecanismo é comum nas espécies florestais, sendo um recurso utilizado para que as sementes sobrevivam por longos períodos, germinando na estação mais propícia ao desenvolvimento da plântula, buscando, através disto, a perpetuação da espécie (FERNANDES; VIEIRA, 1997; FINCH-SAVAGE; LEUBNER-METZGER, 2006).

Para que o processo de germinação ocorra é necessário que as sementes sejam submetidas a condições favoráveis, como temperatura adequada, água e oxigênio. No entanto, muitas espécies não germinam imediatamente quando colocadas sob condições ideais, sendo então consideradas sementes dormentes, necessitando que o bloqueio existente para a germinação seja quebrado. Este bloqueio pode ser dado por diversos fatores, como embrião imaturo ou rudimentar, impermeabilidade do tegumento e ausência de promotores de germinação ou presença de inibidores de germinação (FERREIRA; BORGHETTI, 2004; FINCH-SAVAGE; LEUBNER-METZGER, 2006; TAIZ; ZEIGER, 2009).

A impermeabilidade do tegumento caracteriza um tipo de dormência física comum em diversas sementes, principalmente em plantas das famílias Fabaceae, Malvacea, Geraniacea, Chenopodiacea, Convolvulacea, Solanacea e Liliacea, nesse tipo de dormência a remoção do tegumento através da escarificação química ou mecânica aumenta a permeabilidade à água e a gases, a sensibilidade à luz e à temperatura, e a remoção de inibidores, influenciando no metabolismo e, consequentemente, na quebra da dormência física de sementes (LOPES et al., 2004).

A luz também atua como um importante fator na germinação de sementes em várias espécies. Assim sendo, as espécies cujas sementes necessitam da luz para germinar são chamadas fotoblásticas positivas e as que teriam a germinação inibida pela presença de luz são chamadas fotoblásticas negativas. Há ainda espécies cujas sementes se mostram indiferentes à presença de luz para a germinação sendo consideradas sementes não dormentes (EIRA; MARTINS NETTO, 1998; TAIZ; ZEIGER, 2009).

A espécie Ormosia arborea, conhecida popularmente como tento, ocorre em regiões de Cerrado e é considerada uma espécie com sementes dormentes, pois possui tegumento pouco permeável, restringindo assim a entrada de água na semente, dificultando o processo de germinação. Desta forma, recomenda-se a aplicação metodologias que possibilitem a quebra desta dormência antes da realização da semeadura, visando um aumento do percentual de germinação (LOPES et al., 2006).

Não se têm relatos sobre a superação da dormência tegumentar aliada a luminosidade na germinação de Ormosia arborea nem mesmo a respeito do favorecimento ou não de incidência luminosa em sementes desta espécie. Algumas descrições relacionando a influencia da luminosidade na germinação podem ser encontradas na literatura, para outras espécies florestais, no entanto não foram realizados testes de superação de dormência tegumentar aliados à luminosidade Assim, Miranda et al. (2007) verificaram que as sementes de aroeira (Myracrodruon urundeuva) são fotoblásticas neutras e sementes de ipê (Tabebuia impetiginosa e $T$. serratifolia) germinam mais facilmente na presença de luz (OLIVEIRA et al., 2005).

Alem disso não se tem trabalhos que relatam a capacidade de embebição de sementes de $O$. arborea na ausência de procedimentos de escarificação. Diante disso o presente trabalho teve por objetivo avaliar o efeito de diferentes tratamentos para superação de dormência na germinação de sementes de $O$. arborea.

\section{Material e Métodos}

\section{Coleta do material}

As sementes foram coletadas em fevereiro de 2009 no município de Patos de Minas - MG, tendo como coordenadas geográficas: $18^{\circ} 39^{\prime} \mathrm{S} ; 46^{\circ} 12^{\prime} \mathrm{W}$; e $815 \mathrm{~m}$ de altitude. Esta região caracteriza-se por ter uma classificação climática "Aw", conforme descrito por Köppen (1948), considerado um clima tropical úmido com inverno seco e verão chuvoso. Foram coletadas 
somente as sementes que estavam localizadas sob a planta adulta da espécie Ormosia arborea.

\section{Delineamento experimental e trata- mentos}

Utilizou-se o delineamento inteiramente casualizado, bifatorial $4 \times 2$ (quatro metodologias de superação de dormência e dois fotoperíodos), com quatro repetições.

Para os tratamentos de superação de dormência utilizaram-se: a) imersão em água por $72 \mathrm{~h}$ (LOPES et al., 2006); b) escarificação química com ácido sulfúrico $100 \%$ por $30 \mathrm{~min}$; c) escarificação mecânica (CRUZ et al., 2001); d) controle. Os dois tratamentos de fotoperíodo foram compostos por períodos de $12 \mathrm{~h}$ e Oh de luz.

Para o grupo controle foram utilizadas sementes intactas, colocadas para germinar na presença e na ausência de luz. Já na escarificação química foi utilizada a metodologia proposta por Fernandes e Vieira (1997), onde as sementes foram deixadas durante $30 \mathrm{~min}$, imersas em ácido sulfúrico $100 \%$. Após este período, as sementes foram colocadas em água corrente por aproximadamente $2 \mathrm{~h}$, para a retirada do ácido.

A escarificação mecânica foi efetuada atritandose levemente a porção basal da semente, durante dois segundos, em superfície abrasiva de esmeril elétrico, após esse procedimento, as sementes foram embebidas em béquer com $15 \mathrm{~mL}$ de água por $24 \mathrm{~h}$ (CRUZ et al., 2001). Para o tratamento de imersão, as sementes foram colocadas em béquer com $15 \mathrm{~mL}$ de água destilada, à temperatura constante de $30^{\circ} \mathrm{C}$ durante $72 \mathrm{~h}$ (LOPES et al., 2006).

\section{Instalação do experimento}

Antes da aplicação dos tratamentos, as sementes foram submetidas a tratamento para a desinfestação de microorganismos, localizados na parte externa do tegumento; para isto, estas sementes ficaram imersas durante $2 \mathrm{~min}$ em hipoclorito de sódio a $5 \%$.

Após a aplicação dos tratamentos de superação de dormência as sementes foram divididas em dois grupos, que contemplaram os dois tratamentos de luminosidade, e colocadas em duas câmaras de germinação do tipo B.O.D., uma com fotoperíodo de $12 \mathrm{~h}$ e outra com fotoperíodo de $0 \mathrm{~h}$.

\section{Avaliações}

O teste de germinação foi realizado seguindo as Regras para Análise de Sementes - RAS (BRASIL, 2009). As sementes foram colocadas sobre papel tipo "Germitest" umedecidos com água destilada na proporção de 2,5 vezes o peso do papel seco, os quais, cada repetição formou um rolo de papel com 25 sementes. O critério utilizado para a detecção de sementes germinadas foi à protusão da radícula (FERREIRA, 2007). As sementes foram avaliadas durante quarenta dias, até a estabilização do processo de germinação.

Concomitante ao teste de germinação foi calculado o índice de velocidade de germinação (IVG), equação 1 (Maguire, 1962),

$$
I V G=\frac{G_{1}}{t_{1}}+\frac{G_{2}}{t_{2}}+\frac{G_{3}}{t_{3}} \cdots \frac{G_{n}}{t_{n}}
$$

em que: $I V G$ é o índice de velocidade de germinação; $G$ o número de sementes germinadas e $t$ o tempo transcorrido a partir da semeadura e a germinação, expresso em dias.

\section{Análise estatística}

Os dados de germinação e índice de velocidade de germinação foram transformados em arco seno de raiz de $\mathrm{x} / 100$ e raiz de $\mathrm{x}$, respectivamente, e submetidos aos testes Kolmogorov-Smirnov e de Levene, para a verificação da normalidade e homogeneidade dos dados, e por apresentarem distribuição normal foram submetidos ao teste de Tukey a 5\% de significância.

\section{Resultados}

Não houve interação significativa entre os tratamentos de superação de dormência e fotoperíodo $(p>0,05)$. Entretanto, ao analisar os fatores separadamente, foi possível verificar diferença estatística entre os tratamentos de superação de dormência (Figura 1). O tratamento de 
escarificação química (EQ) proporcionou maiores valores de percentagem de germinação, sendo observados $77 \%$ de germinação para esse tratamento e 49\% nas sementes submetidas à escarificação mecânica (EM).

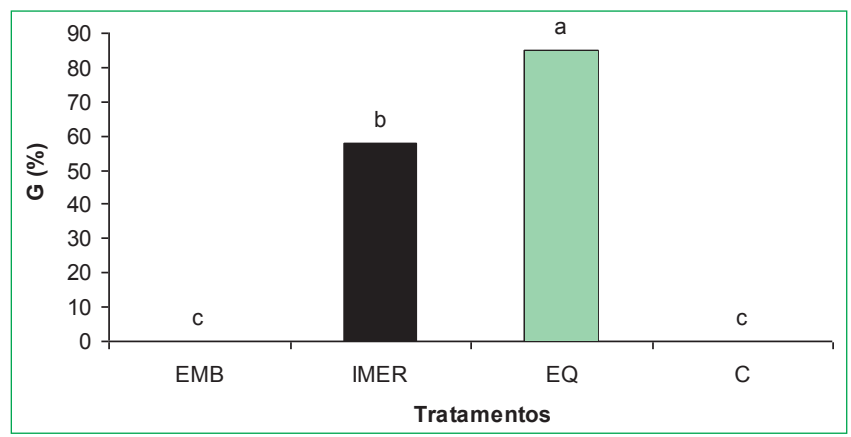

FIGURA 1: Percentagem de germinação $(\mathrm{G} \%)$ em sementes de Ormosia arborea arborea, submetidas a diferentes tratamentos para superação de dormência: IMER (imersão em água por 72h), EM (escarificação mecânica), EQ (escarificação química) e C (controle). UNIPAM, Patos de Minas, MG, 2010. * Médias seguidas pelas mesmas letras não diferem estatisticamente entre si pelo teste de Tukey a 5\% de significância.

Não foram observados efeitos do grupo controle e do tratamento de imersão em água, sobre a germinação de $O$. arborea.

É possível visualizar na Figura 2 que os tratamentos de escarificação mecânica e química determinaram um aumento no índice de velocidade de germinação com relação aos demais tratamentos.

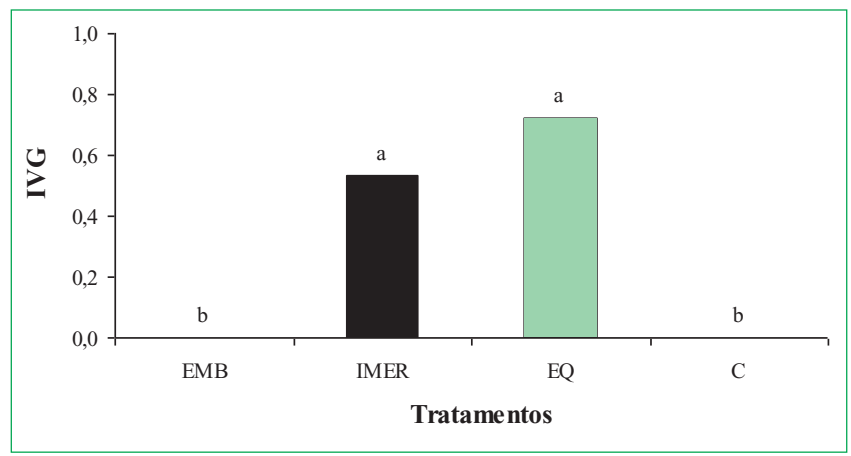

FIGURA 2: Índice de velocidade de germinação (IVG) em sementes de Ormosia arborea, submetidas a diferentes tratamentos para superação de dormência: IMER (imersão em água por 72h), EM (escarificação mecânica), EQ (escarificação química) e C (controle). UNIPAM, Patos de Minas, MG, 2010. *Médias seguidas pelas mesmas letras não diferem estatisticamente entre si pelo teste de Tukey a 5\% de significância.
Com relação à luminosidade, não foram encontradas diferenças significativas entre os dois fotoperíodos analisados (0h e 12h) (Tabela 1) para as variáveis percentagem de germinação e índice de velocidade de germinação.

TABELA 1: Percentagem de Germinação (\%G) e Índice de Velocidade de Germinação (IVG) de sementes de Ormosia arborea, submetidas aos fotoperíodos de 0 e 12 horas.

\begin{tabular}{ccc}
\hline Fotoperíodo (Horas) & $\mathbf{\% G}$ & IVG \\
\hline 0 & $36 \mathrm{a}$ & $0,31 \mathrm{a}$ \\
12 & $27 \mathrm{a}$ & $0,19 \mathrm{a}$ \\
\hline
\end{tabular}

* Médias seguidas pelas mesmas letras nas colunas, não diferem estatisticamente entre si pelo teste de Tukey a 5\% de significância.

\section{Discussão}

Sementes de $O$. arborea apresentam dificuldades de germinação, devido a impermeabilidade do tegumento e segundo Lopes et al. (2004), o funcionamento das atividades fisiológicas da germinação é dependente da capacidade de embebição da semente, pois a água é fator limitante no processo germinativo. Sementes muito duras, cuja testa é impermeável impedem ou limitam a entrada de água e gases para o embrião, e assim retardam a germinação da mesma. A germinação deste tipo de semente na natureza é lenta, pois depende de ação de intempéries, animais entre outros, que promovem a quebra do tegumento e as tornam permeáveis.

O tratamento com escarificação química (EQ) mostrou maior eficiência na superação de dormência da $O$. arborea, provavelmente porque promoveu uma ruptura, total ou parcial, do tegumento da semente, facilitando a entrada de água e desencadeando o processo de germinação, o que não aconteceu com o grupo controle $(\mathrm{C})$ e o tratamento de imersão em água (IMER), que não mostraram eficácia na superação de dormência da espécie estudada. Marques et al. (2004) realizaram estudos semelhantes com a espécie $O$. arborea e também não obtiveram resultados satisfatórios de germinação através da imersão em água e de um grupo sem tratamento. 
Lopes et al. (2006) realizaram experimento com sementes de Ormosia nitida e observaram um aumento significativo na velocidade e percentagem de germinação dessa espécie tratada com escarificação química com ácido sulfúrico $100 \%$ por $10 \mathrm{~m}$, quando comparado com o grupo controle.

De acordo com Lopes et al. (2004), a escarificação mecânica também mostrou resultados positivos em seus experimentos com germinação de $O$. arborea, uma vez que esse tratamento promoveu a entrada de água na semente e facilitou o processo germinativo.

Com relação ao fotoperíodo, não foi observada influência deste no processo de germinação da espécie estudada, demonstrando que essa espécie independe da luz para germinar. Alguns autores realizaram estudos com o efeito da luz sobre a germinação de espécies florestais, no entanto em sementes que não apresentavam dormência tegumentar, e não encontraram diferenças significativas entre sementes germinadas no escuro e com fotoperíodo de $12 \mathrm{~h}$, sugerindo que as espécies sejam fotoblásticas neutras (LEAL FILHO; BORGES, 1992; AMARO et al., 2006; MIRANDA et al., 2007).

Através dos resultados obtidos, foi possível concluir que o tratamento com escarificação química com ácido sulfúrico $100 \%$ por $30 \mathrm{~m}$ é mais eficiente na superação de dormência de $O$. arborea. Além disso, sementes de $O$. arborea sem tratamento e com o tratamento de imersão por $72 \mathrm{~h}$, não apresentam germinação. Com relação à luminosidade, a presença ou ausência de fotoperíodo, associada a tratamentos de superação de dormência mecânica, não exercem influência sobre os valores de germinação e índice de velocidade de germinação dessa espécie, sugerindo que a espécie apresenta apenas dormência tegumentar.

\section{Referências}

AMARO, M. S.; MEDEIROS FILHO, S.; GUIMARÃES, R. M.; TEÓFILO, E. M. Influência da temperatura e regime de luz na germinação de sementes de janaguba (Himatanthus drasticus (Mart.) Plumel.). Ciência e Agrotecnologia, Lavras, v. 30, n. 3, p. 450-457, 2006.

BRASIL. MINISTÉRIO DA AGRICULTURA E REFORMA AGRÁRIA. Regras para análise de sementes. Brasília: SNAD/ DNDV/CLAV, 2009. 365 p.
CRUZ, E. D; MARTINS, F. O.; CARVALHO, J. E. U. Biometria de frutos e sementes e germinação de jatobá-curuba (Hymenaea intermédia Ducke, Leguminosae - Caesalpinoideae). Revista Brasileira de Botânica, São Paulo, v. 24, n. 2, p. 61-165, 2001

EIRA, M. T. S.; MARTINS NETTO, D. A. Germinação e conservação de espécies lenhosas. In: RIBEIRO, J. F. (Ed.). Cerrado: Matas de Galeria. Planaltina: EMBRAPA-CPAC, 1998. $164 \mathrm{p}$.

FERREIRA, A. G.; BORGHETTI, F. Germinação: do básico ao aplicado. Porto Alegre: Artmed, 2004. 323 p.

FERREIRA, W. R. Variabilidade de cinco espécies arbóreas da região de cerrado do Brasil Central para medidas de germinação e emergência. 2007. 116 f. Dissertação (Mestrado em Ecologia e Conservação dos Recursos Naturais) - Universidade Federal de Uberlândia, Uberlândia. 2007.

FERNANDES, G. D.; VIEIRA, I. G. Métodos de quebra de dormência de sementes. 1997. Disponível em: <http://www.ipef. br/sementes/>. Acesso em: 03 setembro 2009.

FINCH-SAVAGE, W. E.; LEUBNER-METZGER, G. L. Seed dormancy and the control of germination. New Phytologist, Oak Ridge, v. 171, p. 501-523, 2006.

KÖEPPEN, W. Climatologia: com um estúdio de los climas de la tierra. México: Fondo de Cultura Econômica, 1948. 478 p.

LEAL FILHO, N.; BORGES, E. E. de L. Influência da temperatura e da luz na germinação de sementes de canudo de pito (Mabea fistulifera Mart.). Revista Brasileira de Sementes, Londrina, v. 14, n. 1, p. 57-60, 1992.

LOPES, J. C.; DIAS, P. C.; MACEDO, C. M. P. Tratamentos de dormência de sementes de Ormosia arborea (Vell.) Harms. Revista Brasil Florestal, Brasília, v. 80, p. 25-35, 2004.

LOPES, J. C.; DIAS, P. C.; MACEDO, C. M. P. Tratamentos para acelerar a germinação e reduzir a deterioração de sementes de Ormosia nitida. Revista Árvore, Viçosa, v. 30, n. 2, p. 171-177, 2006.

MAGUIRE, J. D. Speed germination-aid in selection and evaluation for seedling emergence and vigor. Crop Science, Madison, v. 2, p. 176-177, 1962.

MARQUES, M. A.; RODRIGUES, T. DE J. D.; PAULA, R. C. DE. Germinação de sementes de Ormosia arborea (Vell.) Harms submetidas a diferentes tratamentos pré germinativos. Científica, Jaboticabal, v. 32, n. 2, p. 141-146, 2004.

MIRANDA; W. O.; BRANDÃO, D. O.; ARRUDA, D. M.; NUNES, Y. R. F.; VELOSO, M. D. M.; SILVA, C. H. P. Influência da luz na germinação de sementes de aroeira (Myracrodruon urundeuva) ocorrente em dois fragmentos de florestas estacional decidual no norte de Minas Gerais. In: CONGRESSO DE ECOLOGIA DO BRASIL, VIII, 2007, Caxambu. Resumos... Caxambu: SBE, 2008. Versão eletrônica.

OLIVEIRA, L. M. DE; CARVALHO, M. L. M. DE; SILVA, T. T. DE A.; BORGES, D. I. Temperatura e regime de luz na germinação de sementes de Tabebuia impetiginosa (Martius ex A. P. de Candolle) Standley e T. serratifolia Vahl Nich. - Bignoniaceae. Ciência e Agrotecnologia, Lavras, v. 29, n. 3, s/ paginação, 2005.

TAIZ, L.; ZEIGER, E. Fisiologia vegetal. 4. ed. Porto Alegre: Artmed, 2009. 819 p. 